\title{
Inclined Substrate Deposition of Magnesium Oxide for YBCO-Coated Conductors*
}

\author{
B. Ma, ${ }^{1}$ M. Li, ${ }^{1}$ B. L. Fisher, ${ }^{1}$ R. E. Koritala, ${ }^{1}$ S. E. Dorris, ${ }^{1}$ V. A. Maroni, ${ }^{2}$ \\ and U. Balachandran ${ }^{1}$ \\ ${ }^{1}$ Energy Technology Division, ${ }^{2}$ Chemical Technology Division
}

Argonne National Laboratory, Argonne, IL 60439

April 2002

The submitted manuscript has been created by the
University of Chicago as Operator of Argonne
National Laboratory ("Argonne") under Contract
No. W-31-109-ENG-38 with the U.S. Department
of Energy. The U.S. Government retains for itself,
and others acting on its behalf, a paid-up,
nonexclusive, irrevocable worldwide license in
said article to reproduce, prepare derivative works,
distribute copies to the public, and perform
publicly and display publicly, by or on behalf of
the Government.

PACS codes: 74.72.Bk; 74.76.Bz; 81.15.-z

Keywords: YBCO film, Coated conductor, Inclined substrate deposition, Pulsed laser deposition

Manuscript for Proceedings of the American Ceramic Society, 104th Annual Meeting \& Exposition, St. Louis, Missouri, April 28 - May 1, 2002.

*Work supported by U.S. Department of Energy, Energy Efficiency and Renewable Energy, as part of a program to develop electric power technology, under Contract W-31-109-Eng-38 


\title{
INCLINED SUBSTRATE DEPOSITION OF MAGNESIUM OXIDE FOR YBCO-COATED CONDUCTORS
}

\author{
B. Ma, ${ }^{1}$ M. Li, ${ }^{1}$ B. L. Fisher, ${ }^{1}$ R. E. Koritala, ${ }^{1}$ S. E. Dorris, ${ }^{1}$ V. A. Maroni, ${ }^{2}$ \\ and U. Balachandran ${ }^{1}$ \\ ${ }^{1}$ Energy Technology Division \\ ${ }^{2}$ Chemical Technology Division \\ Argonne National Laboratory \\ Argonne, IL 60439
}

\begin{abstract}
Thin films of $\mathrm{YBa}_{2} \mathrm{Cu}_{3} \mathrm{O}_{7-\mathrm{x}}(\mathrm{YBCO})$ were grown on $\mathrm{MgO}$ buffered metallic substrates by pulsed laser deposition (PLD). The $\mathrm{MgO}$ buffer films, which provide the initial biaxial texture, had been grown on polished Hastelloy C276 (HC) tapes using inclined substrate deposition (ISD). The ISD process is promising for the fabrication of coated superconductor wires because it produces biaxially textured template films on nontextured substrate at high deposition rates. Biaxially aligned $\mathrm{MgO}$ films were deposited at deposition rates of 20 to 100 $\AA /$ sec. The buffer films were deposited on these template films before ablation of the YBCO films by PLD. The microstructure was studied by scanning electron microscopy and atomic force microscopy. X-ray pole figure analysis and $\phi$ - and $\omega$-scans were used for texture characterization. Good in- and out-of-plane textures were observed on the ISD MgO films $(\approx 1.5 \mu \mathrm{m}$ thick). The full width at half maximums were $9.2^{\circ}$ for the $\mathrm{MgO}(002) \phi$-scan and $5.4^{\circ}$ for the $\omega$-scan. Cube-on-cube epitaxial growth of yttria-stabilized zirconia (YSZ) and ceria $\left(\mathrm{CeO}_{2}\right)$ films on the ISD MgO films was also achieved by PLD. A superconducting critical temperature of $90 \mathrm{~K}$, with a sharp transition, and transport critical current density of $>2.5 \times 10^{5} \mathrm{~A} / \mathrm{cm}^{2}$ were obtained on a $0.5-\mu \mathrm{m}$-thick, 0.5 -cm-wide, and 1-cm-long YBCO film with $\mathrm{MgO}$ buffer layer at $77 \mathrm{~K}$ in self-field.
\end{abstract}

\section{INTRODUCTION}

Thin-film superconductors and coated conductor wires have many applications, including high-power transmission cables, high-field magnets, generators, fault-current limiters, magnetic shields, and large-scale microwave devices [1-3]. $\mathrm{YBa}_{2} \mathrm{Cu}_{3} \mathrm{O}_{7-\mathrm{X}}$ (YBCO) can readily be deposited on single-crystal substrates to form biaxially textured (e.g., with both c-axis and in-plane alignment) thin films that carry high critical current density $\left(\mathrm{J}_{\mathrm{c}}\right)$. However, for coatedconductor applications, YBCO films must be coated onto polycrystalline, nontextured, and flexible metal substrates and also be able to carry high $\mathrm{J}_{\mathrm{c}}$. Biaxially textured template films are necessary for successful deposition of 
textured YBCO films on metallic substrates and thus to achieve high $J_{c}$ [4-6]. Research efforts in the past few years have accelerated the processing, fabrication, and manufacturing of high-temperature coated conductors to meet the needs of the U.S. electric power industry [1-3,7]. Several techniques, including ion-beamassisted deposition (IBAD) [8-10], rolling-assisted biaxially textured substrates (RABiTS) [11,12], and inclined-substrate deposition (ISD) [13-15], were developed. Compared to the first two processes, ISD produces textured films at high deposition rates $(20-100 \AA / \mathrm{sec})$ and is independent of the recrystallization properties of the metallic substrates. It is also simpler and easier to accomplish, without the need of an assisting ion source or complicated heat treatment.

We grew biaxially textured $\mathrm{MgO}$ thin films on mechanically polished Hastelloy C276 (HC) substrates by ISD using an e-beam evaporation system. To decrease the surface roughness of the as-deposited ISD $\mathrm{MgO}$ films, an additional thin layer of $\mathrm{MgO}$ was deposited at an elevated temperature and a zero inclination angle. YSZ and $\mathrm{CeO}_{2}$ buffer layers were epitaxially deposited on these ISD-MgObuffered substrates with an excimer laser system before YBCO ablation. The surface morphology of the films was investigated by scanning electron microscopy (SEM), and atomic force microscopy (AFM) was used to determine surface roughness. Raman spectroscopy was measured on selected samples to study the phase integrity of the YBCO films. X-ray pole figure analysis and $\phi-$ and $\omega$-scans were conducted to analyze texture. The superconducting transition temperature $\left(T_{c}\right)$ was determined inductively, and $J_{c}$ was measured by the fourpoint method at $77 \mathrm{~K}$ in self-field. In this paper, we discuss the growth mechanism, crystalline texture, microstructure, and superconducting properties of YBCO deposited on biaxially textured ISD $\mathrm{MgO}$ buffer layers fabricated on polished HC substrates.

\section{EXPERIMENTAL PROCEDURE}

Mechanically polished $\mathrm{HC}$ coupons measuring $\approx 0.1 \mathrm{~mm}$ thick, $\approx 5 \mathrm{~mm}$ wide, and $1 \mathrm{~cm}$ long were used as substrates for the deposition of ISD $\mathrm{MgO}$ template films, buffer layers, and YBCO films. The ISD $\mathrm{MgO}$ films were grown from a $\mathrm{MgO}$ source evaporated by an electron beam. Fused lumps of $\mathrm{MgO}$ (Alfa Aesar, 99.95\% metal basis, 3-12 $\mathrm{mm}$ pieces) were used as target material. The HC substrate was attached using silver paste to a tiltable sample stage that was above the e-beam evaporator, as shown in Fig. 1. The angle between substrate normal and the $\mathrm{MgO}$ vapor direction, the inclination angle, was varied between 10 and $70^{\circ}$. Base pressure of the evaporation chamber was $\approx 1 \times 10^{-7}$ torr. High-purity oxygen flow was introduced into the system at $\approx 3 \mathrm{sccm}$ to maintain an operating pressure of $\approx 1 \times 10^{-5}$ torr. A crystal monitor was mounted besides the sample stage to monitor and control the deposition rate. High deposition rates of 20 to $100 \AA / \mathrm{sec}$ were used, and the substrate temperature was maintained between room temperature and $50^{\circ} \mathrm{C}$ during deposition. After deposition of the ISD films, a thin layer of $\mathrm{MgO}$ was deposited at a zero degree inclination angle at elevated temperatures to reduce the surface roughness. 


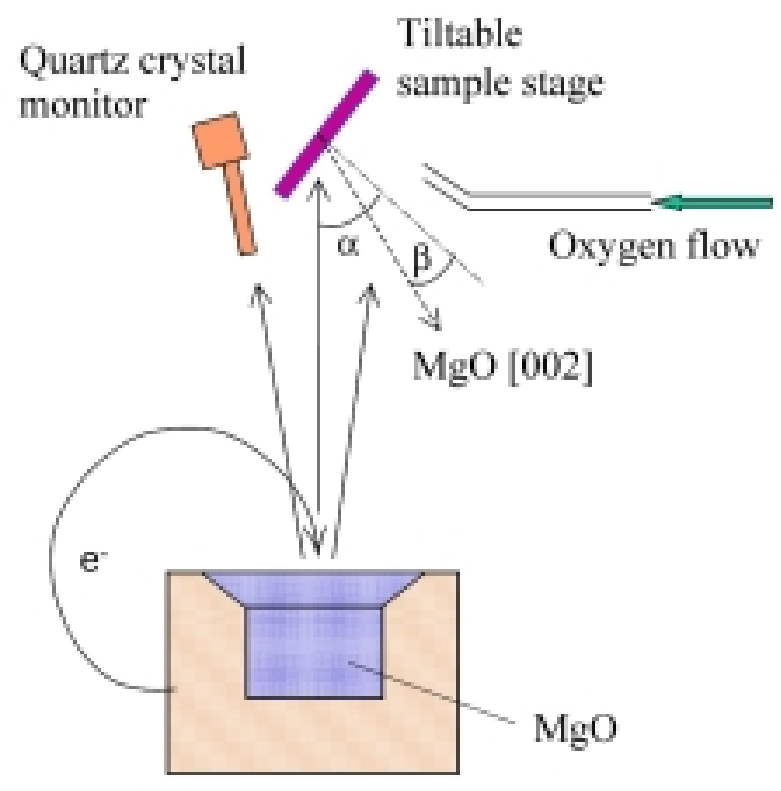

E-beam evaporator

Figure 1. Schematic illustration of experimental setup for ISD MgO.

Buffer films and YBCO films were deposited by pulsed laser deposition (PLD) with a Lambda Physik LPX 210i excimer laser using a $\mathrm{Kr}-\mathrm{F}_{2}$ gas premixture as the lasing medium. Figure 2 shows a schematic illustration of the PLD system, which includes an optical beam raster to produce films with better uniformity over broader area. The laser beam was focused at the target through a quartz lens (1000-mm focal length) coated with anti-reflective coating and was reflected by a mirror that was mounted as part of the beam raster. The reflected beam hits the target at a $45^{\circ}$ incident angle. The rotating target carrousel carries four targets to accommodate the needs for multiple layer ablation without breaking the vacuum. Commercial targets (Superconductive Components, all better than $99.99 \%$ pure), $45 \mathrm{~mm}$ in diameter and $6 \mathrm{~mm}$ in thickness, were used. The substrates were attached to a heatable sample stage with silver paste and heated to high temperature $\left(700-800^{\circ} \mathrm{C}\right)$ during deposition. The base pressure of the chamber was $\approx 1 \times 10^{-5}$ torr. The desired operating pressure (100-300 mtorr) was maintained by flowing ultra-high-purity oxygen at $\approx 10 \mathrm{sccm}$ and pumping the chamber with a molecular turbo pump. The size of the laser spot focused at the rotating target was $\approx 12$ $\mathrm{mm}^{2}$, which resulted in an energy density of $\approx 1.5 \mathrm{~J} / \mathrm{cm}^{2}$. The distance between the target and the substrates was $\approx 7 \mathrm{~cm}$. 


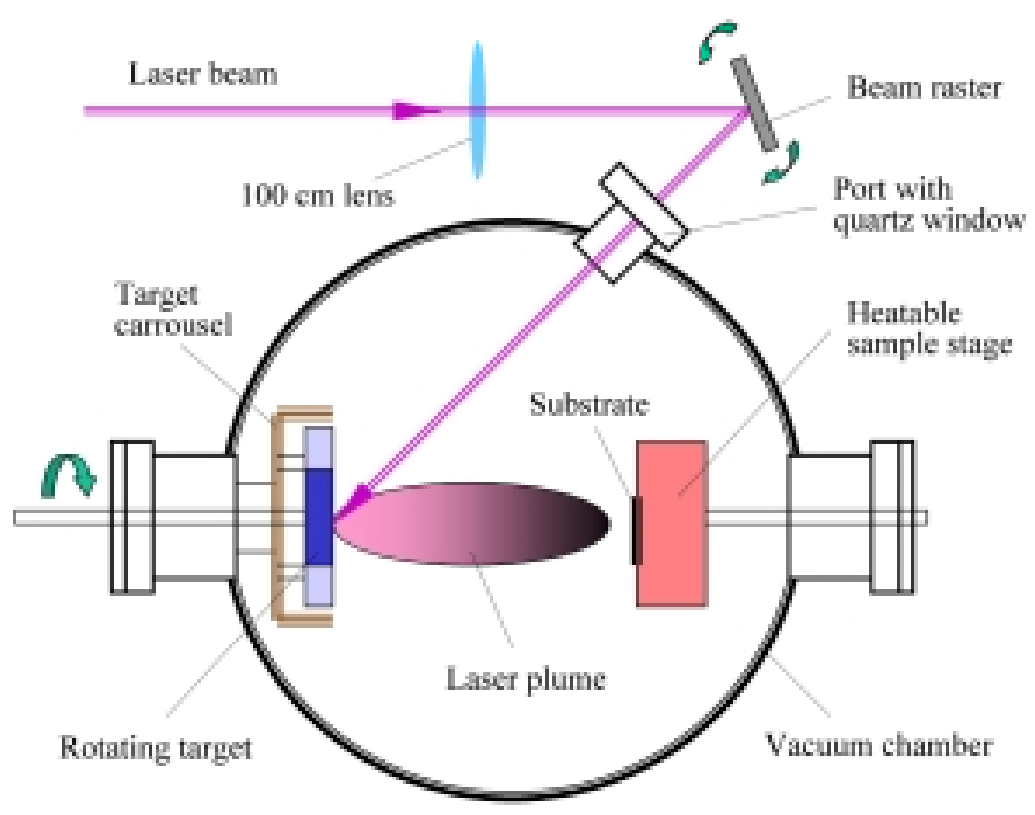

Figure 2. Schematic illustration of PLD system.

$T_{c}$ and $J_{c}$ were determined by an inductive method, and transport $\mathrm{J}_{\mathrm{c}}$ was measured by the four-point transport method at $77 \mathrm{~K}$ in liquid nitrogen using an 1 $\mu \mathrm{V} / \mathrm{mm}$ criterion. The inductive method is a standard characterization tool used to measure the superconducting properties of YBCO films. Thin-film superconductor samples were placed between a pair of primary and secondary coils with inner diameters of $\approx 1 \mathrm{~mm}$ and outer diameters of $\approx 5 \mathrm{~mm}$. Alternating current of $1 \mathrm{kHz}$ was introduced to the primary coil and detected from the secondary coil by a lockin amplifier (Stanford Research Systems SR830 DSP). Samples used for transport measurements were first coated with $2-\mu \mathrm{m}$-thick silver by e-beam evaporation and then annealed in flowing high-purity oxygen at $400^{\circ} \mathrm{C}$ for $2 \mathrm{~h}$.

The film texture was characterized by X-ray diffraction pole figure analysis with $\mathrm{Cu}-\mathrm{K}_{\alpha}$ radiation. For the ISD $\mathrm{MgO}$ films and subsequently deposited buffer films, in-plane texture was characterized by the full-width at half maximum (FWHM) of the $\phi$-scan for (002) reflection, and the out-of-plane texture was characterized by the FWHM of the $\omega$-scan at the [001] pole for the same reflection. As for the YBCO films, in-plane texture was measured by the FWHM of the YBCO (103) $\phi$-scan, and out-of-plane texture was measured by the FWHM of the YBCO (005) $\omega$-scan. Plan-view and fracture cross-sectional SEM (Hitachi S4700-II) were conducted to study the morphology of MgO films. Surface roughness was measured by taping-mode AFM with a Digital Instruments Dimension 3100 SPM system. 


\section{RESULTS AND DISCUSSION}

Typical X-ray pole figures of an ISD $\mathrm{MgO}$ film deposited at an inclination angle $\alpha=55^{\circ}$, with a thickness of $1.5 \mu \mathrm{m}$, are shown in Fig. 3. Unlike the YSZ films prepared by inclined-substrate PLD [13], where the (001) planes are nearly parallel to the substrate surface, the [001] axis of the ISD MgO buffer layer is tilted away from the substrate normal. The asymmetric distribution of the pole peaks reveals that the $\mathrm{MgO}(001)$ planes have a tilt angle $\beta$ toward the deposition direction. These ISD MgO films exhibit good texture; distinct in-plane alignment can be seen by the well-defined poles for not only the [001] axis but also the [010] and [100] axes in Fig. 3a. Out-of-plane alignment was characterized by the $\omega$-scan; data were taken at the [001] pole. The tilt angle, as determined from the chi angle value of the [001] reflection in the $\mathrm{MgO}(002)$ pole figure, was $\approx 32^{\circ}$.

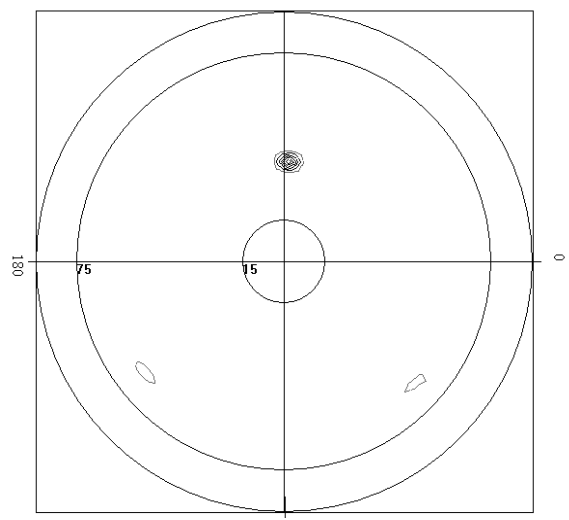

(a)

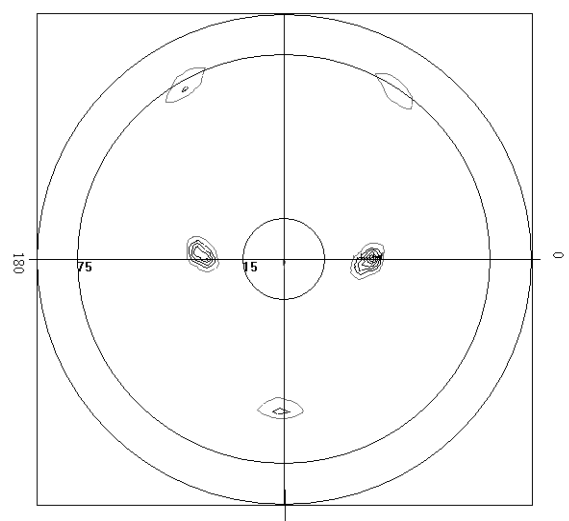

(b)

Figure 3. (a) $\mathrm{MgO}(002)$ and (b) $\mathrm{MgO}$ (220) pole figures for $\approx 1.5-\mu \mathrm{m}$-thick ISD $\mathrm{MgO}$ film deposited at room temperature with $\alpha=55^{\circ}$.

Plan-view SEM revealed (Fig. 4a) a roof-tile structure for a $\mathrm{MgO}$ film deposited at room temperature with $\alpha=55^{\circ}$. Columnar grains nearly perpendicular to the substrate surface were observed on the cross-sectional fracture surface (Fig. $4 \mathrm{~b})$. The $\mathrm{MgO}$ grain size increased when the film grew for the first $0.25-\mu \mathrm{m}$ thickness; it then became stabilized at $\approx 0.1 \mu \mathrm{m}$, without noticeable change in size when the film grew thicker. To reduce surface roughness, an additional thin layer of $\mathrm{MgO}$ was deposited on the ISD $\mathrm{MgO}$ films at elevated temperatures (600$800^{\circ} \mathrm{C}$ ) by e-beam evaporation at $\alpha=0$. Figures $4 \mathrm{c}$ and $4 \mathrm{~d}$ are SEM images of the top plan-view and fracture cross-sectional view of a $0.5-\mu m$-thick homoepitaxial $\mathrm{MgO}$ layer deposited at $700^{\circ} \mathrm{C}$ on $1.5-\mu \mathrm{m}$-thick ISD MgO. Surface smoothness of the film was improved. Plate-shaped grains were formed during the homoepitaxial deposition at $700^{\circ} \mathrm{C}$, in contrast to columnar grains during ISD deposition at room temperature, as shown in Fig. $4 \mathrm{~d}$. Figure 5 shows the AFM images of ISD MgO films with and without a homoepitaxial $\mathrm{MgO}$ layer. AFM analysis revealed that the root-mean-square (RMS) surface roughness of the $\mathrm{MgO}$ films improved from $\approx 28 \mathrm{~nm}$ to $\approx 10 \mathrm{~nm}$ after deposition of the homoepitaxial layer. 


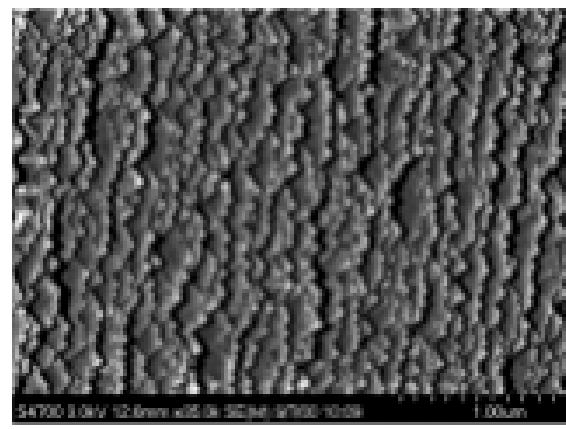

(a)

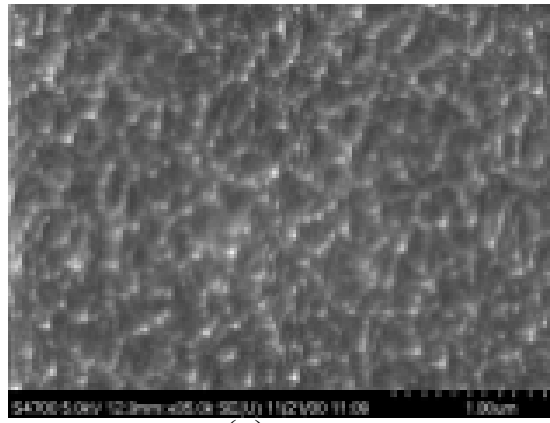

(c)

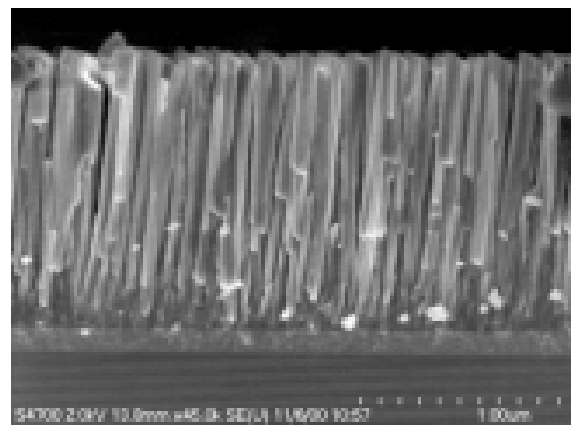

(b)

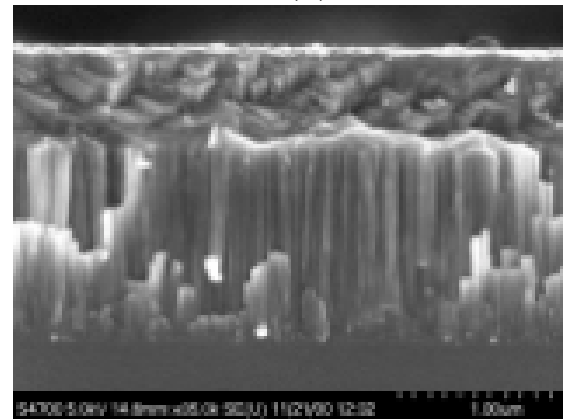

(d)

Figure 4. (a) Plan view and (b) cross-sectional SEM images of ISD MgO film deposited at room temperature with $\alpha=55^{\circ}$; (c) Plan view and (d) cross-sectional $\mathrm{SEM}$ images of $\mathrm{MgO}$ film after depositing additional layer of $\mathrm{MgO}$ by e-beam evaporation at $700^{\circ} \mathrm{C}$ with $\alpha=0^{\circ}$.

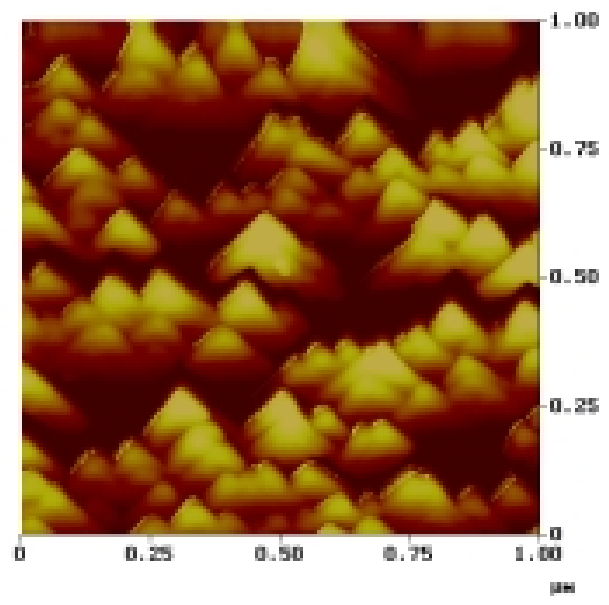

(a)

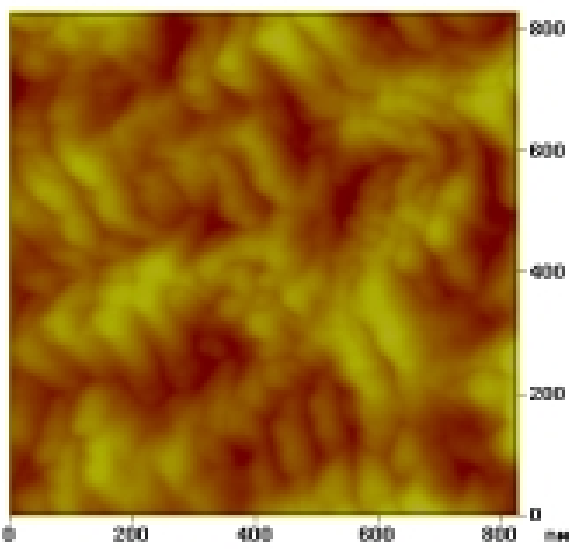

(b)

Figure 5. AFM images of (a) ISD and (b) homoepitaxial $\mathrm{MgO}$ films. 
Figure 6 shows a TEM image and selected area diffraction (SAD) pattern of $\mathrm{MgO}$ columnar grain in a film deposited with $\alpha=55^{\circ}$. The top facet of $\mathrm{MgO}$ grains is a (002) plane. Film morphology and texture evolution in the ISD MgO films can be understood from the self-shadowing effect. It has been demonstrated [16] that in-plane texture during polycrystalline film growth develops through a combination of fast growth along a certain crystallographic direction and the selfshadowing that occurs when deposition is at an inclined angle. In the case of $\mathrm{MgO}$, the fast growth plane is $\{200\}$ [17]. Because maximizing the (002) faces can decrease the surface free energy, the $\{200\}$ plane is also the equilibrium crystal habit, as confirmed by the cubic morphology exhibited in the $\mathrm{MgO}$ film [18]. With deposition at an inclined angle, the $\{200\}$ plane rotates toward the vapor source, so the (002) surface grows faster than other crystalline faces.
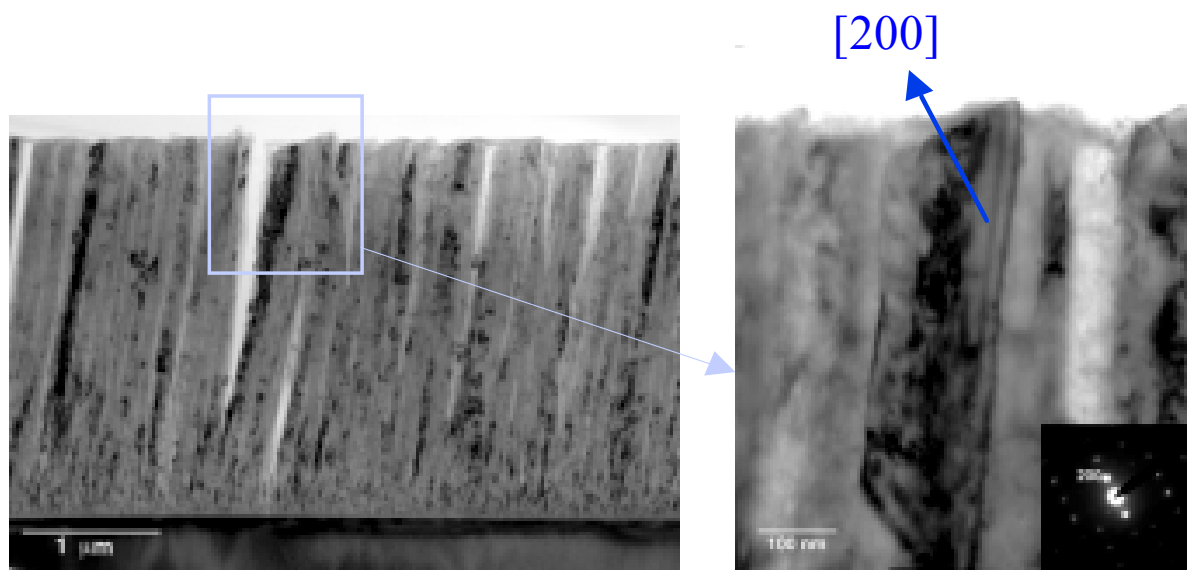

Figure 6. TEM cross-sectional view and selected area diffraction demonstrating that columnar grain terminates with a (200) crystal face in an ISD MgO film.
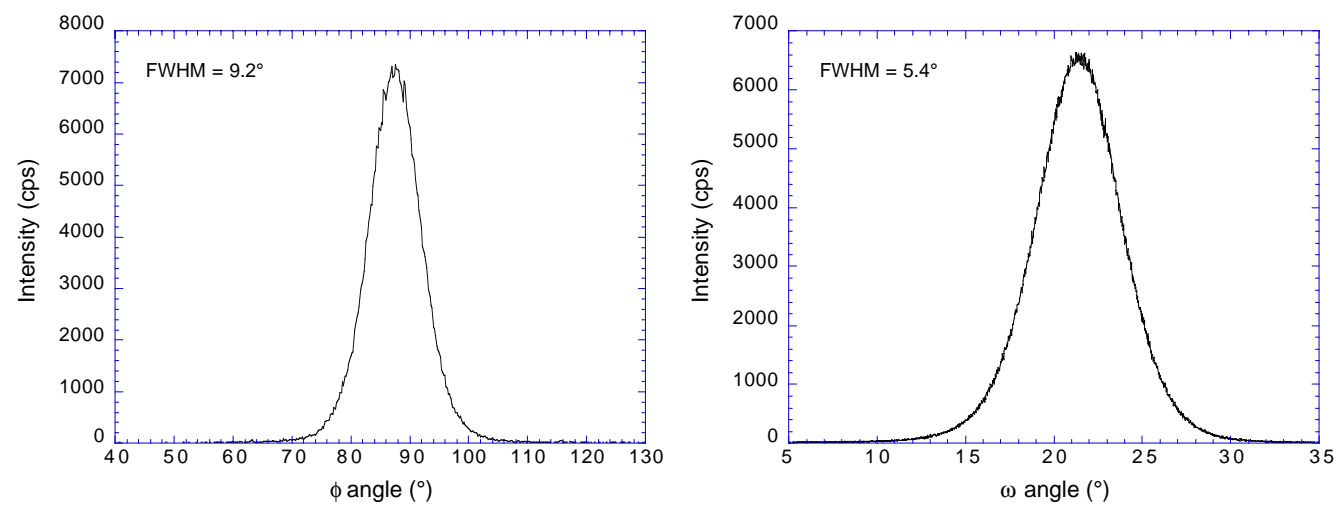

Figure 7. $\mathrm{MgO}$ (002) (a) $\phi$-scan and (b) $\omega$-scan patterns after homoepitaxial growth of $0.5-\mu \mathrm{m}$-thick $\mathrm{MgO}$ layer on ISD $\mathrm{MgO}$ film at elevated temperature. 
Figure 7 shows typical $\phi$-scan and $\omega$-scan patterns for $\mathrm{MgO}(002)$ after homoepitaxially growing a $0.5-\mu \mathrm{m}$-thick $\mathrm{MgO}$ layer on ISD $\mathrm{MgO}$ film at elevated temperature. Both in- and out-of-plane textures were improved after deposition of the homoepitaxial $\mathrm{MgO}$ layer. FWHMs were reduced from 12.2 to 9.2 and from 6.3 to $5.4^{\circ}$, respectively, in the $\mathrm{MgO}(002) \phi$-scan and $\omega$-scan. To study the effect of film thickness on film texture, we deposited ISD $\mathrm{MgO}$ films of various thickness using the same inclination angle $\left(55^{\circ}\right)$ and deposition rate $(120 \mathrm{~nm} / \mathrm{min}$. $)$. Following the deposition of the ISD $\mathrm{MgO}$ layer, a homoepitaxial layer of $\approx 0.5 \mu \mathrm{m}$ was deposited. The samples with different ISD layers and the same thickness of homoepitaxial layer of $\mathrm{MgO}$ were used for texture analysis. Figure 8 shows the FWHM of $\mathrm{MgO}(002) \phi$-scan as a function of ISD layer thickness. We found that the film thickness of ISD layer has little effect on the texture of a final for samples with an initial ISD layer thickness of $0.25 \mu \mathrm{m}$ or thicker. The value of $0.25 \mu \mathrm{m}$ appears to be the critical thickness for growing high-quality ISD $\mathrm{MgO}$ films.

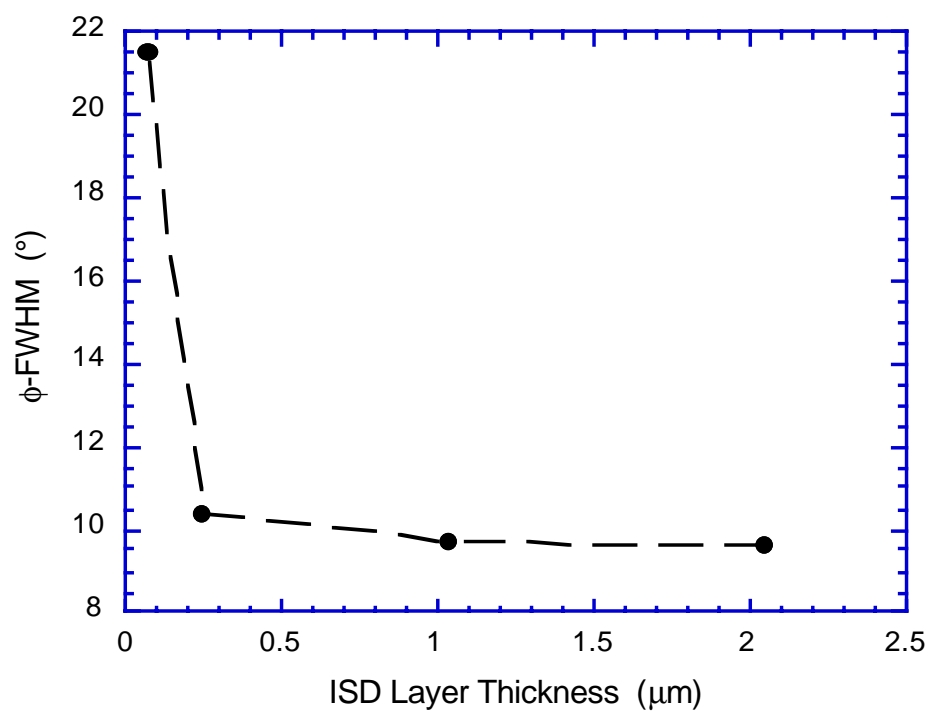

Figure 8. In-plane texture dependence on ISD layer thickness.

The YBCO films were deposited on ISD MgO-buffered HC substrates using the conditions listed in Table 1. To improve lattice mismatch and therefore enhance the superconducting properties of $\mathrm{YBCO}$ films, the $\mathrm{YSZ}$ and $\mathrm{CeO}_{2}$ buffer layers were deposited by PLD. Details of the buffer layer architecture will be reported elsewhere [19]. Figure 9 shows a Raman spectrum of the YBCO deposited on ISD MgO-buffered HC substrate. Only a sharp peak at $340 \mathrm{~cm}^{-1}$ and a weak peak at $500 \mathrm{~cm}^{-1}$ were observed in the Raman shift region from 200 to $800 \mathrm{~cm}^{-1}$. Both the 340 and the $500 \mathrm{~cm}^{-1}$ peaks are associated with YBCO-123 phase [20]. Raman data revealed that the YBCO film was of good quality, lacking secondary phases or cation disorder. 


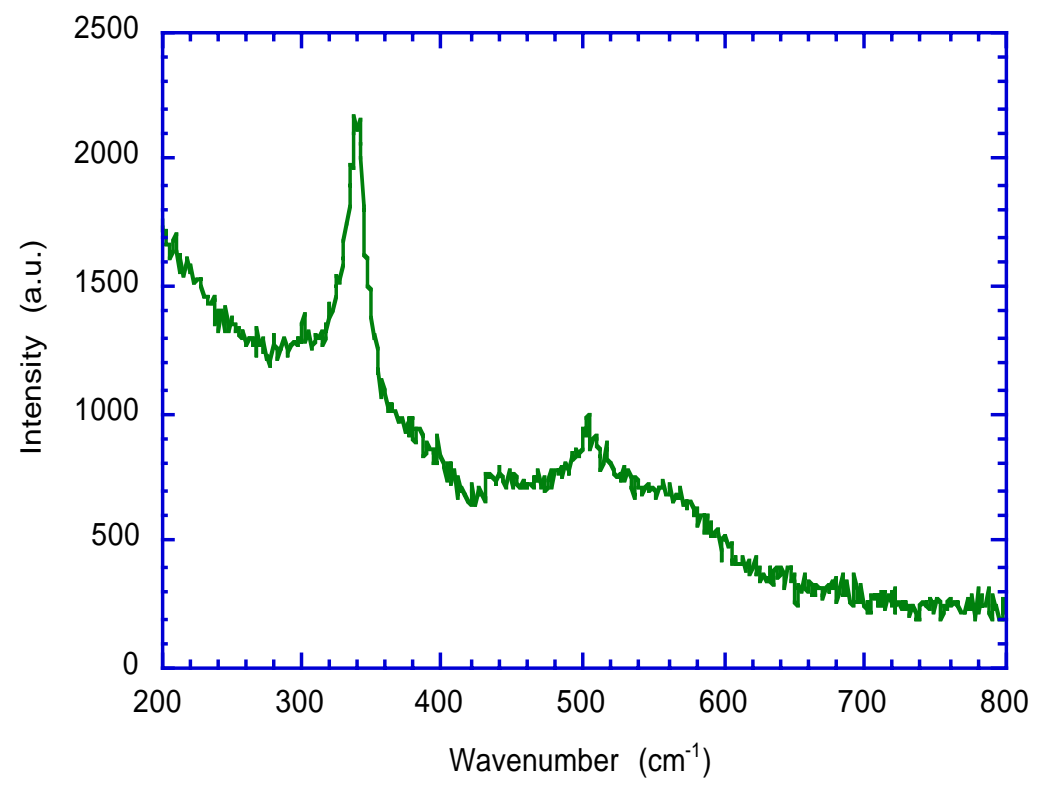

Figure 9. Raman spectrum of a YBCO film deposited on ISD MgO-buffered HC substrate.

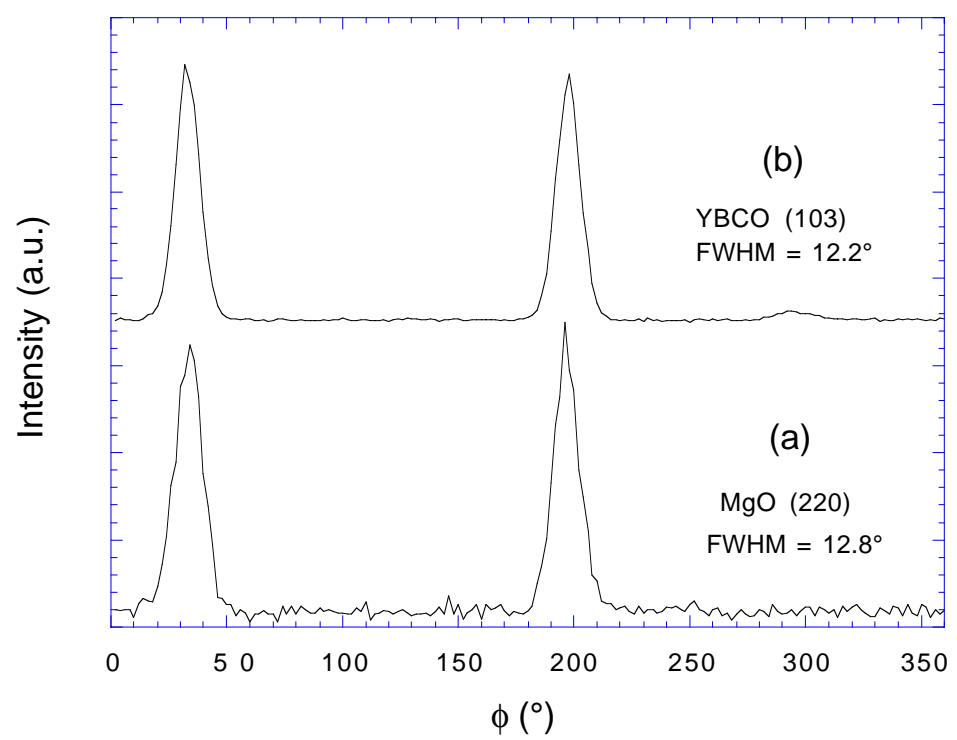

Figure 10. $\phi$-scan patterns of $\mathrm{MgO}$ (220) and YBCO (103) showing epitaxial growth. 
TABLE 1. Conditions used for epitaxial growth of YBCO by PLD

\begin{tabular}{ll} 
Laser wavelength & $248 \mathrm{~nm}(\mathrm{Kr}-\mathrm{F})$ \\
Repetition rate & $8-70 \mathrm{~Hz}$ \\
Pulse width & $25 \mathrm{~ns}$ \\
Energy density & $1-3 \mathrm{~J} / \mathrm{cm}^{2}$ \\
Substrate temperature & $700-800^{\circ} \mathrm{C}$ \\
Operating pressure & $100-300 \mathrm{mtorr}$ \\
Oxygen flow rate & $10 \mathrm{sccm}$ \\
Target-to-substrate distance & $4-8 \mathrm{~cm}$ \\
\hline
\end{tabular}

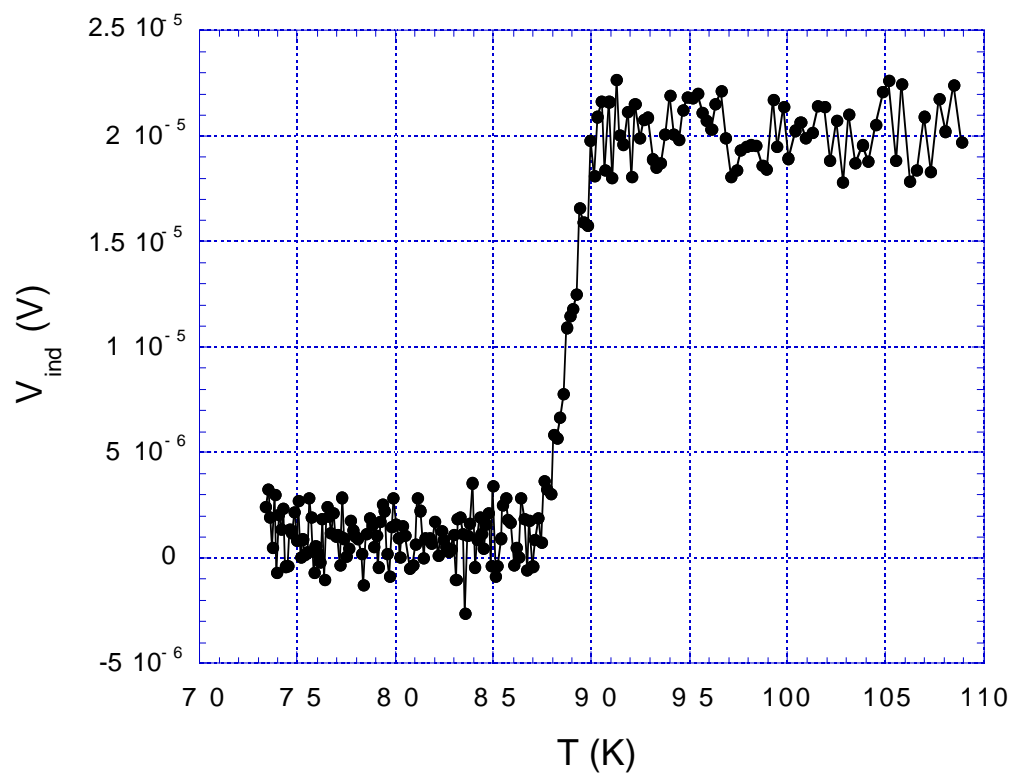

Figure 11. Critical-temperature transition curve for YBCO film deposited on ISD-MgO-buffered HC substrate.

Figure 10 shows $\phi$-scans for the $\mathrm{MgO}$ (220) and YBCO (103) grown on the $\mathrm{MgO}$-buffered $\mathrm{HC}$ substrate; it reveals epitaxial growth, with cubic-on-cubic biaxial alignment: YBCO [001] // MgO [001] and YBCO [110] // MgO [100] (or $\mathrm{MgO}[010])$. The FWHMs of the YBCO films were generally $1-2^{\circ}$ smaller than those of the underlying $\mathrm{MgO}$ films; the FWHMs of the $\mathrm{MgO}$ buffer layers on which the YBCO films had been deposited were also slightly smaller. We obtained a $\mathrm{T}_{\mathrm{c}}$ of $90 \mathrm{~K}$ for a $0.5-\mu \mathrm{m}$-thick YBCO film deposited on an ISD MgObuffered $\mathrm{HC}$ substrate. From the inductive measurements, Fig. 11 shows that the superconducting transition was complete at $88 \mathrm{~K}$. The measured transport $\mathrm{J}_{\mathrm{c}}$ was $>2.5 \times 10^{5} \mathrm{~A} / \mathrm{cm}^{2}$ at $77 \mathrm{~K}$ in self-field on a sample that was $0.5 \mu \mathrm{m}$ thick, $0.5 \mathrm{~cm}$ wide, and $1 \mathrm{~cm}$ long. 


\section{CONCLUSIONS}

Biaxially textured $\mathrm{MgO}$ films were successfully grown by the ISD method, which is much more time-efficient for fabrication of buffer layers than is the IBAD YSZ process. The MgO films grown by the ISD process contained columnar grains that were terminated at the surface by (002) planes. Plan-view SEM revealed a roof-tile-shaped structure. The surface roughness and biaxial texture of the ISD $\mathrm{MgO}$ thin films were significantly improved by deposition of an additional thin layer of $\mathrm{MgO}$ at elevated temperature. Surface roughness of the $\mathrm{MgO}$ films reduced from $\approx 28 \mathrm{~nm}$ to $\approx 10 \mathrm{~nm}$ as measured by AFM, and FWHMs were reduced from 12.2 to 9.2 and from 6.3 to $5.4^{\circ}$ in the $\mathrm{MgO}(002) \phi$-scan and $\omega$-scan, respectively, after deposition of a $\approx 5$ - $\mu \mathrm{m}$-thick homoepitaxial layer at $700^{\circ} \mathrm{C}$. The value of $0.25 \mu \mathrm{m}$ appears to be a critical thickness for growing high quality ISD $\mathrm{MgO}$ films. Raman data revealed high-quality and phase integrity for the YBCO films grown on ISD-MgO-buffered $\mathrm{HC}$ substrates. $\mathrm{A} \mathrm{T}_{\mathrm{c}}$ of $90 \mathrm{~K}$ with a sharp superconducting transition, and a $\mathrm{J}_{\mathrm{c}}>2.5 \times 10^{5} \mathrm{~A} / \mathrm{cm}^{2}$ at $77 \mathrm{~K}$ in self-field were measured on YBCO films fabricated using ISD architecture. These results demonstrate that biaxially textured ISD $\mathrm{MgO}$ buffer layers deposited on metal substrates are excellent candidates for fabrication of high-quality YBCO-coated conductors.

\section{ACKNOWLEDGMENTS}

SEM/TEM analysis was performed in the Electron Microscopy Center for Materials Research at Argonne National Laboratory. This work was supported by the U.S. Department of Energy (DOE), Energy Efficiency and Renewable Energy, as part of a DOE program to develop electric power technology, under Contract W-31-109-Eng-38.

\section{REFERENCES}

1. D. K. Finnemore, K. E. Gray, M. P. Maley, D. O. Welch, D. K. Christen, and D. M. Kroeger, Physica C, 320, 1-8 (1999).

2. Y. Iijima and K. Matsumoto, Supercond. Sci. Technol., 13, 68-81 (2000).

3. J. O. Willis, P. N. Arendt, S. R. Foltyn, Q. X. Jia, J. R. Groves, R. F. DePaula, P. C. Dowden, E. J. Peterson, T. G. Holesinger, J. Y. Coulter, M. Ma, M. P. Maley, and D. E. Peterson, Physica C, 335, 73-77 (2000).

4. D. Dimos, P. Chaudhari, J. Mannhart, and F. K. Legouges, Phys. Rev. Lett., 61, 219-222 (1988).

5. D. Dimos, P. Chaudhari, and J. Mannhart, Phys. Rev. B, 41, 4038-4049 (1990).

6. X. D. Wu, R. E. Muenchausen, S. Foltyn, R. C. Estler, R. C. Dye, C. Flamme, N. S. Nogar, A. R. Garcia, J. Martin, and J. Tesmer, Appl. Phys. Lett., 56, 1481-1483 (1990).

7. "Coated Conductor Technology Development Roadmap," U.S. Department of Energy, Superconductivity for Electric System Program (Aug. 2001).

8. Y. Iijima, N. Tanabe, O. Kohno, and Y. Okeno, Appl. Phys. Lett., 60, 769-771 (1992).

9. R. P. Reade, P. Berdahl, R. E. Russo, and S. M. Garrison, Appl. Phys. Lett., 61, 2231-2233 (1992). 
10. C. P. Wang, K. B. Do, M. R. Beasley, T. H. Geballe, and R. H. Hammond, Appl. Phys. Lett., 71, 2955-2957 (1997).

11. D. P. Norton, A. Goyal, J. D. Budai, D. K. Christen, D. M. Kroger, E. D. Specht, Q. He, B. Saffain, M. Paranthaman, C. E. Klabunde, D. F. Lee, B. C. Sales, and F. A. List, Science, 274, 755 (1996).

12. M. Schindl, J.-Y. Genoud, H. L. Suo, M. Dhalle, E. Walker, and R. Flukiger, IEEE Trans. Appl. Supercond., 11, 3313-3316 (2001).

13. K. Hasegawa, K. Fujino, H. Mukai, M. Konishi, K. Hayashi, K. Sato, S. Honjo, Y. Sato, H. Ishii, and Y. Iwata, Appl. Superconductivity, 4, 487-493 (1996).

14. M. Bauer, R. Semerad, and H. Kinder, IEEE Trans. Appl. Supercon., 9, 15021505 (1999).

15. B. Ma, M. Li, Y. A. Jee, B. L. Fisher, and U. Balachandran, Physica C, 366, 270-276 (2002).

16. O. P. Karpenko, J. C. Bilello, and S. M. Yalisove, J. Appl. Phys., 82, 13971403 (1997).

17. A. F. Moodie and C. E. Warble, J. Crystal Growth, 10, 26-38 (1971).

18. R. E. Koritala, M. P. Chudzik, Z. Luo, D. J. Miller, C. R. Kannewurf, and U. Balachandran, IEEE Trans. Appl. Supercond., 11, 3473-3476 (2001).

19. U. Balachandran, B. Ma, M. Li, B. L. Fisher, R. E. Koritala, R. Erck, and S. E. Dorris, to be published in proceedings of Materials Research Society Fall 2001 Meeting, Boston, Nov. 25-29, 2001.

20. M. N. Iliev, P.X. Zhang, H. U. Habermeier, and M. Cardona, J. Alloys

Compounds, 251, 99-102 (1997). 